\title{
Maternal uniparental disomy of chromosome 16 in a case of spontaneous abortion
}

Received: 4 November 2003/ Accepted: 7 January 2004 / Published online: 2 March 2004

(C) The Japan Society of Human Genetics and Springer-Verlag 2004

\begin{abstract}
To investigate the involvement of uniparental disomies (UPDs) in spontaneous abortions, we analyzed in detail the polymorphism of microsatellites on each chromosome in cases of abortion. Of the 52 spontaneous abortions investigated, 25 had a normal karyotype. The polymorphic analysis of these cases revealed that, in the villi from 24 of the 25 cases, biparental patterns were present in informative microsatellites in all autosomes. In the remaining case with a 46, XX karyotype (case 18), however, the informative patterns of the microsatellites of chromosome 16 appeared to be both of maternal origin. The results also showed that the region from the distal end of the short arm to near the middle point of the long arm of chromosome 16 (pter to D16S3107) were heterozygous, and those of the remaining region of the long arm (D16S3018 to qter) were homozygous. That is, this fetus had maternal isodisomy and heterodisomy of chromosome 16 , originating from a maternal, meiosis I non-disjunction of dyad 16 that accompanied a crossover at near the middle point of the long arm. The present finding suggests that some UPDs may become a cause for spontaneous abortions.
\end{abstract}

Y. Kondo $\cdot$ S. Tsukishiro $\cdot$ M. Tanemura

M. Sugiura-Ogasawara $\cdot$ K. Suzumori

Department of Obstetrics and Gynecology,

Nagoya City University Medical School,

Nagoya 467-8601, Japan

Present address: Y. Kondo

Department of Obstetrics and Gynecology,

Moriyama Municipal Hospital,

Nagoya 463-8567, Japan

S. Sonta $(\square)$

Department of Genetics,

Institute for Developmental Research,

Aichi Human Service Center, 713-8 Kamiya-cho,

Kasugai, Aichi 480-0392, Japan

E-mail: ssonta@inst-hsc.jp

Tel.: +81-568880811

Fax: + 81-568880829
Keywords Uniparental disomy (UPD) - Chromosome 16 - Spontaneous abortion - Microsatellite polymorphism $\cdot$ Maternal origin $\cdot$ Normal karyotype

\section{Introduction}

Among all recognized pregnancies, about $10-15 \%$ end in spontaneous abortion. About half of these abortions are caused by chromosomal abnormalities, including many kinds of aneuploidy, polyploidy, monosomy of the X-chromosome, and so on (Lauritsen 1976; Hassold et al. 1980; Kajii et al. 1980; Warburton et al. 1980). Some of the chromosomal abnormalities detected in these abortions are also seen in liveborns, and the frequency of pregnancies with each of these chromosomal abnormalities that end in abortion is far higher than the frequency of those which produce liveborns (Epstein 1986; Gardner and Sutherland 1996). The findings have indicated that chromosomally unbalanced embryos are mostly eliminated as spontaneous abortion during the developmental stages.

On the other hand, the causes of other cases of abortions of fetuses with a normal karyotype are mostly unknown, although immunological and other defects (Gill 1986; Chiu et al. 1996; Kaider et al. 1999) have been detected in some cases. However, the fact that typical chromosomal abnormalities account for a large portion of spontaneous abortions suggests that functional, structural, and constitutional abnormalities, which are undetectable by usual chromosomal analysis, may contribute to these abortions. These abnormalities could be, for example, a deletion of fine chromosomal segments including genes essential to fetal development, abnormal inactivation of the X-chromosome, or abnormal imprinting. Uniparental disomy (UPD) of chromosomes having an imprinting region is also included in this category. UPD cases cannot usually be detected by chromosome banding, except for a few cases with remarkable heteromorphism of the 
chromosomes. To-date, only a few UPD cases have been found among spontaneous abortions (Shaffer et al. 1998; Smith et al. 1998; Fritz et al. 2001). In the present study, we analyzed the chromosomal origin of spontaneous abortions with a normal karyotype, using microsatellite polymorphic markers to investigate the involvement of UPDs, and found one case of UPD for chromosome 16 in 52 abortions.

\section{Materials and methods}

Cases of abortions analyzed

We obtained 143 cases of spontaneous abortion from the patients admitted to the Department of Obstetrics and Gynecology, Nagoya City University School of Medicine, Nagoya and from the Cell Bank, constructed by a Health Sciences Research Grant for Research on Human Genome (H10-Genome-008) from the Ministry of Health and Welfare of Japan. Of the 143 cases, the 52 that were miscarriages of first-time pregnancies at weeks 7-9 were analyzed in the present study. After the women and their spouses in these cases had been given understandable and detailed information on this study and its purposes, all agreed to allow the use of parental and fetal materials for analysis. Peripheral blood of the woman and her spouse and chorionic villi from the abortion were obtained in each case.

\section{Chromosomal analysis}

Part of the villi from the abortions was cultured and prepared for chromosomal analysis after 7-23 days. Peripheral blood lymphocytes from the patient and her spouse were also cultured and harvested conventionally for chromosomal analysis.

DNA extraction and polymorphic analysis of microsatellites

Genomic DNA was extracted from the villi of the aborted fetuses and the blood of the women and their spouses by the standard methods. Two hundred polymorphic microsatellite markers on about every $2 \mathrm{Mb}$ in all autosomes and the $\mathrm{X}$ chromosome were selected from the Genethon collections (Dib et al. 1996). Most of the primer sets used in this study were gratefully accepted gifts from Prof. Y. Nakamura of the Medical Institute of Tokyo University, and other primers were synthesized. Genotypes of the fetus and the parents for each marker locus were determined using the DNA-sequencer-assisted method with fluorescent microsatellite marker DNAs (Fujimoto et al. 1998; Alf Express Fragment Manager, Pharmacia Biotech). When the results suggestive of UPD for certain chromosomes were obtained, further analyses using other microsatellite markers on the same chromosome were carried out to clearly identify the parental chromosome origin. To examine the exact stage occurred, a non-disjunction and the existence of recombination on chromosome 16 during maternal meiosis, we detected the exact arrangement of allelic microsatellite patterns of each chromosome 16 in the mother of the aborted fetus (case 18) by analysis of the microsatellite patterns of the grandparents on the mother's side.

\section{Results}

Of the 52 spontaneous abortions investigated, 27 $(51.9 \%)$ had chromosomal abnormalities: $47, \mathrm{XX}$ or
$\mathrm{XY},+16$ and $45, \mathrm{X}$ in five cases; $47, \mathrm{XX}$ or $\mathrm{XY},+22$ in three cases; $47, \mathrm{XX}$ or $\mathrm{XY},+9$ and $69, \mathrm{XXY}$ in two cases; and $47, \mathrm{XX},+2,47, \mathrm{XY},+10,47, \mathrm{XX},+13,47, \mathrm{XX},+15$, $47, \mathrm{XY},+18,47, \mathrm{XY},+21,48, \mathrm{XX},+16,+22,69, \mathrm{XXX}$ $70, \mathrm{XXY},+22,92, \mathrm{XXYY}$ in one case. Polymorphic analysis of microsatellites was carried out in the remaining 25 cases with normal karyotypes: $46, \mathrm{XX}$ in 13 cases and 46,XY in 12 cases. Polymorphic analysis of the villi from 24 of the 25 cases revealed biparental patterns, one paternal and the other maternal, in informative microsatellites in all autosomes and in the $\mathrm{X}$-chromosome of the 46,XX cases. The results thus indicated that every paired chromosome originated from one paternal and one maternal chromosome.

In the remaining case of $46, \mathrm{XX}$ (case 18 ), the microsatellite polymorphic patterns of all paired autosomes and the X-chromosome, except chromosome 16, indicated to be one paternal and one maternal chromosome; however, the informative patterns of three microsatellites of chromosome 16 were both of maternal origin. Further polymorphic analysis of this case was carried out using other primer sets for chromosome 16 (Fig. 1). The exact arrangement of microsatellite patterns in each chromosome 16 in the mother was detected by analysis of the grandparents on the mother's side (data not shown). Eight microsatellites showed informative patterns clearly indicating both maternal origin, and all patterns of the other 17 microsatellites were consistent with maternal origin. The results also showed that the microsatellite patterns in the region from the end of the short arm to about the middle part of the long arm of chromosome 16 (D16S423 to D16S3107) were heterozygous, while those in the remaining region from that point to the distal end of the long arm (D16S3018 to D16S413) were homozygous. That is, the microsatellite analyses indicated that this fetus had maternal isodisomy and heterodisomy of chromosome 16 . The results also revealed that both chromosomes 16 originated from a maternal, meiosis I non-disjunction of dyad 16; one accompanied one meiotic recombination at about the middle of the long arm, and the other had no recombination. In this case, all the 100 cells analyzed had a normal karyotype of $46, \mathrm{XX}$, and there was no evidence of mosaicism including trisomy 16.

Case 18 was the first pregnancy of a 32-year-old woman. Her spouse was 33 years old. The karyotypes of the woman and her spouse were normal. There was nothing remarkable either before or during the early period of pregnancy. When the pregnancy was confirmed at 6 weeks and 2 days, the gestational sac was about $16 \mathrm{~mm}$ and heartbeat was confirmed. The fetus was diagnosed as having a stopped heartbeat in the eighth week of pregnancy, and aborted finally at 8 weeks and 4 days of pregnancy. In the aborted materials, the fetus could not be found. Abnormal figures indicating signs of hydatidiform, and cystic features were not found in the chorionic villi obtained from the abortion in this case. 
Fig. 1a, b Polymorphic patterns of microsatellites of chromosome 16 seen in the aborted fetus and the parents in case 18. a List of primers that showed informative patterns of microsatellite polymorphism and the size of PCR products (bp). The arrangement of markers and the locus of the centromere are roughly shown. b Polymorphic patterns of microsatellites in the fetus (case 18) and the parents. The arrangement of microsatellite patterns in each chromosome 16 of the mother was detected by analysis of the grandparents on the mother's side (data not shown). The polymorphic analysis indicates that this is a case of maternal iso/ heterodisomy of chromosome 16 a

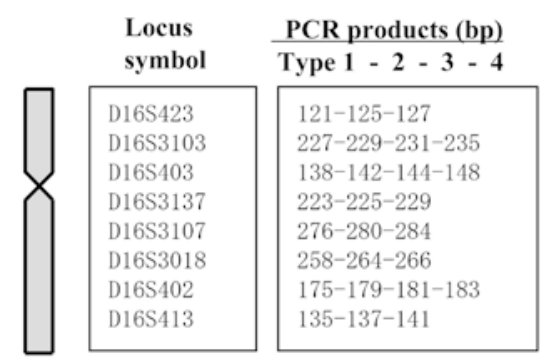

16 b

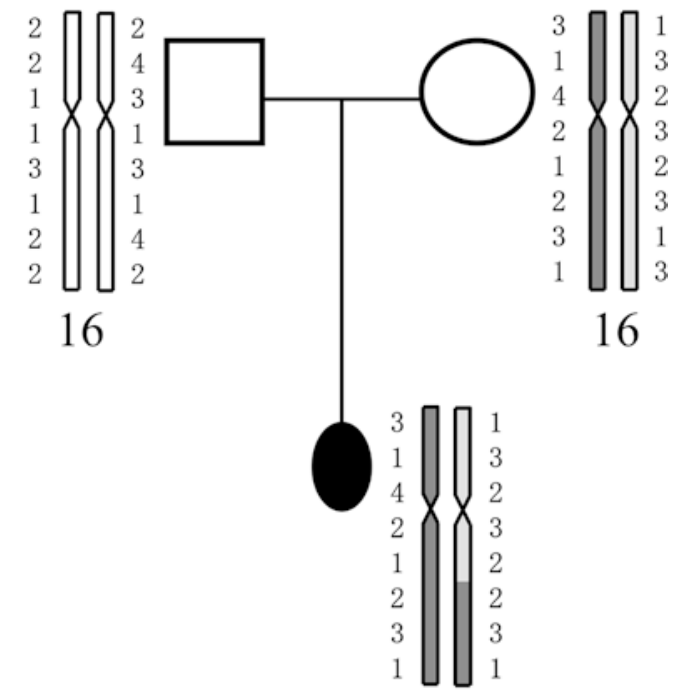

16

\section{Discussion}

The frequency and distribution of chromosome abnormalities in the present study of spontaneous abortions were similar to the data in the previous studies (Carr and Gedeon 1977; Hassold et al. 1980; Kajii et al. 1980). Whereas the frequency of polyploidies was comparatively low, and the respective frequency of some abnormalities differed as compared with the previous studies, these discrepancies may be due to a small number of cases in the present analysis.

Full UPDs for various chromosomes have been detected by DNA polymorphic analysis and other methods in human individuals with chromosomal abnormalities, imprinting disturbances, and non-Mendelian inheritance of recessive genes. In a previous review (Engel 1998), maternal (mat) UPDs of chromosomes 1, 2, 4, 6, 7, 9, 10, 13-16, 21, 22, and X, and paternal (pat) UPDs of chromosomes $1,5-8,11,13-16,20-22$, and $\mathrm{X}$ have been reported. Among these UPDs, some cases, such as of UPDs $1,13,21$, and 22, which do not relate to anomalous transmission of recessive genes, had almost no clinical features (Ledbetter and Engel 1995; Morison and Reeve 1998). In contrast, abnormal clinical features have been distinctly shown in cases of both pat and mat UPDs 14 and 15 (Nicholls et al. 1989; Antonarakis et al. 1993; Bottani et al. 1994; Cotter et al. 1997). Abnormal clinical features were also shown in cases of pat UPDs 6 and 11 (Henry et al. 1991; Temple et al. 1995) and in cases of mat UPDs 2, 7, and 16 (Vaughan et al. 1994; Kotzot et al. 1995; Johnston et al. 1996). In particular, serious clinical features have been described in some cases of mat UPD 2 showing phenotypes of severe growth retardation, renal failure, and pulmonary dysplasia (Webb et al. 1996; Shaffer et al. 1997) of pat UPD
14 showing skeletal dysplasia and thoracic narrowing (Cotter et al. 1997), and of mat UPD 16 showing congenital heart and digestive-tract anomalies and stunted growth (Vaughan et al. 1994). Furthermore, no UPDs of chromosomes 3,12, and 17-19 have been found in any case to-date. These findings, therefore, suggest the possibility that some UPD cases may also exhibit serious abnormalities before birth, including during the periods of embryogenesis and early fetal development. Previous mouse studies have clearly indicated that some UPDs affect the development of embryos and placentas (Ferguson-Smith et al. 1991). In humans, however, it has not been sufficiently ascertained whether UPDs affect development before birth, including early embryogenesis, implantation, organogenesis, and differentiation, through the involvement of some imprinting genes. In the present study, we documented the first case of mat UPD 16 in a human spontaneous abortion. This finding indicates the possibility that UPDs may affect the development of the fetus.

To-date, many UPD 16 cases in fetuses and liveborns have been reported in the literature. Whereas one was a child of pat UPD 16 without any clinical abnormality (Kohlhase et al. 2000), mat UPD 16 cases showed clinical abnormalities such as body stalk anomaly, intrauterine growth retardation, imperforate anus, and congenital heart disease (Kalousek et al. 1993; Vaughan et al. 1994; O'Riordan et al. 1996; Abu-Amero et al. 1999; Chan et al. 2000). Mat UPD 16 has frequently been associated with trisomy 16-confined placental mosaicism (CPM) (Kalousek et al. 1993; Yong et al. 2003). In the present study, the analysis of a large number of cells from cultured chorionic villi excluded the possibility of CPM and, thus, suggests that the case of UPD 16 was probably derived from a trisomy rescue 
event at the first mitotic stage or from fertilization between disomic and nullisomic gametes. The result also suggests the possibility that the clinical or pathological effects of full mat UPD 16 on pregnancies may differ from cases of mat UPD 16 associated with CPM of trisomy 16.

The mechanism of UPDs is first considered to be derived from the trisomy rescue event (Cassidy et al. 1992; Purvis-Smith et al. 1992). Full trisomy 16 is the major cause of spontaneous abortions, and the frequency of trisomy 16 seen in spontaneous abortions may be higher than that of any other trisomy. Therefore, UPD 16 may be due to the process of trisomy rescue. One can also consider UPD by fertilization between nullisomic and disomic gametes for the same chromosome, but the frequency of UPDs produced by this mechanism may be low. Though the results confirmed a low incidence of UPD in spontaneous abortion (Fritz et al. 2001), the possibility of UPD 16 causing spontaneous abortion has not been excluded.

Most trisomies seen in liveborns, including trisomies 18 and 21, are also found in spontaneous abortions at several times the rate in liveborns; for example, trisomy 21 is found at about 3.3 times the rate in liveborns and trisomy 18 at more than 15 times, according to the calculations of the data of Carr and Gedeon (1977) and Hook and Hamerton (1977) with the assumption that spontaneous abortions occur at the rate of about $15 \%$ of conceptions. These facts also suggest that UPDs seen in liveborns with congenital abnormalities may become a cause for spontaneous abortions, in the same way as trisomies. However, the relationship between UPDs and abortion is still not well understood. In the literature todate, there have been only two reported UPD cases (UPDs 9 and 21) among spontaneous abortions (Fritz et al. 2001), and the present case is the first report of UPD 16 in spontaneous abortions. So far, there have been four studies searching for UPD in consecutively corrected spontaneous abortions of a normal karyotype (Shaffer et al. 1998; Smith et al. 1998; Fritz et al. 2001; present study). The combined frequency of UPD cases from these studies is $1.65 \%(3 / 182)$, which confirms a low incidence of UPDs in spontaneous abortions (Fritz et al. 2001). The data indicated that while the frequency of UPDs in spontaneous abortions may be low, the possibility of UPDs causing spontaneous abortion has not been excluded.

However, there is still an insufficient number of detailed studies on the origin of whole chromosomes in spontaneous abortions, using DNA polymorphic analyses and other means. In order to clarify the relationship between UPDs and spontaneous abortions, or the effects of UPDs during the developmental stages in humans, further investigations of abortions using DNA polymorphic markers and other means are needed. Through these studies, one may discover unknown imprinting regions in human chromosomes and genes only activated during limited periods such as embryogenesis and fetal development.
Acknowledgements The authors would like to thank Professor Yusuke Nakamura of the Medical Institute of Tokyo University, Tokyo, for proffering oligonucleotide primers capable of detecting many polymorphic microsatellite markers. This work was supported by a Grant-in-Aid for Scientific Research from the Ministry of Education, Science, Sports, and Culture of Japan (No. 13470356) and a Health Sciences Research Grant for Research on Human Genome (H10-Genome-008) from the Ministry of Health and Welfare of Japan.

\section{References}

Abu-Amero SN, Ali Z, Abu-Amero KK, Stanier P, Moore GE (1999) An analysis of common isodisomic regions in five mUPD 16 probands. J Med Genet 36:204-207

Antonarakis SE, Blouin J-L, Maher J, Avramopoulos D, Thomas G, Talbot CC Jr (1993) Maternal uniparental disomy for human chromosome 14, due to loss of a chromosome 14 from somatic cells with $\mathrm{t}(13 ; 14)$ trisomy 14 . Am J Hum Genet 52:1145-1152

Bottani A, Robinson WP, DeLozier Blanchet CD, Engel E, Morris MA, Schmitt B, Thun-Hohenstein L, Schinzel A (1994) Angelman syndrome due to paternal uniparental disomy of chromosome 15: a milder phenotype? Am J Med Genet 51:35-40

Carr DH, Gedeon M (1977) Population cytogenetics of human abortuses. In: Hook EB, Porter IH (eds) Population cytogenetics: studies in humans. Academic, New York, pp 1-9

Cassidy SB, Lai L-W, Erickson RP, Magnuson L, Eappen T, Gendron R, Herrmann J (1992) Trisomy 15 with loss of the paternal 15 as a cause of Prader-Willi syndrome due to maternal disomy. Am J Hum Genet 51:701-708

Chan Y, Silverman N, Jackson L, Wapner R, Wallerstein R (2000) Maternal uniparental disomy of chromosome 16 and body stalk anomaly. Am J Med Genet 94:284-286

Chiu L, Nishimura M, Ishii Y, Nieda M, Maeshima M, Takedani Y, Shibata Y, Tadokoro K, Juji T (1996) Enhancement of the expression of progesterone receptor on progesteronetreated lymphocytes after immunotherapy in unexplained recurrent spontaneous abortion. Am J Reprod Immunol 35:552-557

Cotter PD, Kaffe S, McCurdy LD, Jhaverzi M, Willner JP, Hirschhorn K (1997) Paternal uniparental disomy for chromosome 14: a case report and review. Am J Med Genet 70:74-79

Dib C, Faure S, Fizames C, Marc S, Vignal A, Heilig R, Lathrop M, Morrissette J, Gyapay G, Weissenbach J (1996) A comprehensive genetic map of the human genome based on 5,264 microsatellites. Nature 380:152-154

Engel E (1998) Uniparental disomies in unselected populations. Am J Hum Genet 63:962-966

Epstein CJ (1986) The consequences of chromosome imbalance, principles, mechanism and models. Cambridge University Press, Cambridge

Ferguson-Smith AC, Cattanach BM, Barton SC, Beechey CV, Surani MA (1991) Embryological and molecular investigations of parental imprinting on mouse chromosome 7. Nature 351:667-670

Fritz B, Aslan M, Kalscheuer V, Ramsing M, Saar K, Fuchs B, Rehder H (2001) Low incidence of UPD in spontaneous abortions beyond the 5th gestational week. Eur J Hum Genet 9:910-916

Fujimoto M, Kantaputra PN, Ikegawa S, Fukushima Y, Sonta S, Matsuo M, Ishida T, Matsumoto T, Kondo S, Tomita H, Deng HX, D'urso M, Rinaldi MM, Ventruto V, Takagi T, Nakamura Y, Niikawa N (1998) The gene for mesomelic dysplasia Kantaputra type is mapped to chromosome 2q24-q32. J Hum Genet 43:32-36

Gardner RJM, Sutherland GR (1996) Chromosome abnormalities and genetic counseling, 2nd edn. Oxford University Press, New York 
Gill TJ III (1986) Immunological and genetic factors influencing pregnancy and development. Am J Reprod Immunol Microbiol 10:116-120

Hassold T, Chen N, Funkhouser J, Jooss T, Manuel B, Matsuura J, Matsuyama A, Wilson C, Yamane JA, Jacobs PA (1980) A cytogenetic study of 1,000 spontaneous abortions. Ann Hum Genet 44:151-178

Henry I, Bonaiti-Pellie C, Chehensse V, Beldjord C, Schwartz C, Utermann G, Junien C (1991) Uniparental paternal disomy in a genetic cancer-predisposing syndrome. Nature 351:665-667

Hook EB, Hamerton JL (1977) The frequency of chromosomal abnormalities detected in consecutive newborn studies-differences between studies-results by sex and by severity of phenotypic involvement. In: Hook EB, Porter IH (eds) Population cytogenetics: studies in humans. Academic, New York, pp 79-92

Johnston KM, Baker JC, Egli CA, McCaskill C, Shaffer LG (1996) Maternal uniparental isodisomy of chromosome 2 in a child with growth retardation, hypospadias and a cytogenetic abnormality. Am J Hum Genet Suppl 59:A95

Kaider AS, Kaider BD, Janowicz PB, Roussev RG (1999) Immunodiagnostic evaluation in women with reproductive failure. Am J Reprod Immunol 42:335-246

Kajii T, Ferrier A, Niikawa N, Takahara H, Ohama K, Avirachan S (1980) Anatomic and chromosomal anomalies in 639 spontaneous abortuses. Hum Genet 55:87-98

Kalousek DK, Langlois S, Barrett I, Yam I, Wilson DR, HowardPeebles PN, Johnson MP, Giorgiutti E (1993) Uniparental disomy for chromosome 16 in humans. Am J Hum Genet 52:8-16

Kohlhase J, Janssen B, Weidenauer K, Harms K, Bartels I (2000) First confirmed case with paternal uniparental disomy of chromosome 16. Am J Med Genet 91:190-191

Kotzot D, Schmitt S, Bernasconi F, Robinson WP, Lurie IW, Ilyina $\mathrm{H}$, Mehes $\mathrm{K}$, Hamel BC, Otten BJ, Hergersberg M, Hamel BC, Otten BJ, Hergersberg M (1995) Uniparental disomy 7 in Silver-Russell syndrome and primordial growth retardation. Hum Mol Genet 4:583-587

Lauritsen JG (1976) Aetiology of spontaneous abortion. A cytogenetic and epidemiological study of 288 abortuses and their parents. Acta Obstet Gynecol Scand Suppl 52:1-29

Ledbetter DH, Engel E (1995) Uniparental disomy in humans: development of an imprinting map and its implications for prenatal diagnosis. Hum Mol Genet 4:1757-1764
Morison IM, Reeve AE (1998) A catalogue of imprinted genes and parent-of-origin effects in humans and animals. Hum Mol Genet 7:1599-1609

Nicholls RD, Knoll JHM, Butler MG, Karani S, Lalande M (1989) Genetic imprinting suggested by maternal heterodisomy in nondeletion Prader-Willi syndrome. Nature 342:281-285

O'Riordan S, Greenough A, Moore GE, Bennett P, Nicolaides KH (1996) Case report: uniparental disomy 16 in association with congenital heart disease. Prenat Diagn 16:963-965

Purvis-Smith SG, Saville T, Manass S, Yip M-Y, Lam-Po-Tang PRL, Duffy B, Johnston H, Leigh D, McDonald B (1992) Uniparental disomy 15 resulting from "correction" of an initial trisomy 15. Am J Hum Genet 50:1348-1350

Shaffer LG, McCaskill C, Egli CA, Baker JC, Johnston KM (1997) Is there phenotype associated with maternal isodisomy for chromosome 2 in the presence of two isochromosomes? Am $\mathbf{J}$ Hum Genet 61:461-462

Shaffer LG, McCaskill C, Adkins K, Hassold TJ (1998) Systematic search for uniparental disomy in early fetal losses: the results and a review of the literature. Am J Med Genet 79:366-372

Smith MJ, Creasy MR, Clarke A, Upadhyaya M (1998) Sex ratio and absence of uniparental disomy in spontaneous abortions with a normal karyotype. Clin Genet 53:258-261

Temple IK, James RS, Crolla JA, Sitch FL, Jacobs PA, Howell WM, Betts P, Baum JD, Shield JP (1995) An imprinted gene(s) for diabetes? Nat Genet 9:110-112

Vaughan J, Ali Z, Bower S, Bennett P, Chard T, Moore G (1994) Human maternal uniparental disomy for chromosome 16 and fetal development. Prenat Diagn 14:751-756

Warburton D, Stein Z, Kline S, Susser M (1980) Chromosome abnormalities in spontaneous abortions: data from the New York City study. In: Porter IH, Hook EB (eds) Human embryonic and fatal death. Academic, New York, pp 261268

Webb AL, Sturgiss S, Warwicker P, Robson SC, Goodship JA, Wolstenholme J (1996) Maternal uniparental disomy for chromosome 2 in association with confined placental mosaicism for trisomy 2 and severe intrauterine growth retardation. Prenat Diagn 16:958-962

Yong PJ, Barrett IJ, Kalousek DK, Robinson WP (2003) Clinical aspects, prenatal diagnosis, and pathogenesis of trisomy 16 mosaicism. J Med Genet 40:175-182 